\title{
Análise dos Procedimentos e Critérios Necessários à Valoração de Propriedade Intelectual para a Transferência de Tecnologia no Âmbito dos Núcleos de Inovação Tecnológica (NITs)
}

\author{
Analysis of the Procedures and Criteria Necessary for Intellectual \\ Property Valuation for Technology Transference Under Technological \\ Innovation Centers
}

\author{
Ana Rita Fonseca Ferreira ${ }^{1}$ \\ André Luis Rocha de Souza ${ }^{1}$ \\ ${ }^{1}$ Instituto Federal de Educação, Ciência e Tecnologia, Salvador, BA, Brasil
}

\begin{abstract}
Resumo
A pesquisa teve por objetivo investigar os procedimentos e os critérios necessários para a valoração de patentes no âmbito dos NITs. Para tanto, realizou-se uma pesquisa exploratória, de natureza bibliográfica e documental, com uma abordagem qualitativa, descritiva e analítica. Os resultados evidenciaram que a valoração de patente é fator importante ao processo de negociação de patentes. Observou-se também que os procedimentos e os critérios aplicados para mensurar o valor monetário de patentes no âmbito dos NITs incluem definir o tipo de contrato, a análise do ciclo de vida da patente - com a finalidade de identificar o impacto dos retornos esperados. Ademais, fazse necessário identificar em qual estágio o invento está sendo valorado, considerando que a valoração sofre estágios diferentes. Por fim, é necessário, também, identificar o nível de prontidão tecnológica, pois o nível de maturidade impacta no valor da tecnologia.
\end{abstract}

Palavras-chave: Propriedade Intelectual. Transferência de Tecnologia. Valoração de Patentes. Núcleo de Inovação Tecnológica (NIT). Exploração Comercial.

\begin{abstract}
The aim of this research was to analyze the procedures and criteria necessary for the valuation of patents under the Technological Innovation Centers. Therefore, an exploratory research of bibliographic and documentary nature was carried out, with a qualitative, descriptive and analytical approach. The results showed that patent valuation is an important factor in the patent negotiation process. It was also observed that the procedures and criteria applied to measure the monetary value of patents under the Technological Innovation Centers include definition of the contract type, and patent life cycle analysis - in order to analyze the impact of the expected returns. Finally, it is necessary to identify the stage in which the invention is being evaluated, considering that valuation presents different stages, as well as identify the technological readiness level, since the value of the technology will depend on its stage.
\end{abstract}

Keywords: Intellectual Property. Technology Transference. Patent Valuation. Technological Innovation Centers. Commercial Exploration.

Área Tecnológica: Propriedade Intelectual. 


\section{Introdução}

Nas últimas décadas, o mundo tem assistido a avanços significativos na produção científica e tecnológica, e, como consequência disso, observa-se um aumento no número dos pedidos de proteção dos inventos (PAIVA; SHIKI, 2017). Esse aumento visa a assegurar a propriedade dessa criação, de natureza intelectual, por meio do pedido do registro de patentes que é o instrumento relevante para induzir o desenvolvimento tecnológico, com reflexos positivos na economia e na sociedade (ADRIANO; ANTUNES, 2017).

Destarte, a propriedade intelectual consiste no direito concedido aos criadores de inventos, seja uma tecnologia, os modelos de utilidades ou outros inventos. Assim, pretende proteger a criação de eventuais explorações indevidas: conceder ao inventor o direito de explorar, de forma exclusiva, a sua criação; licenciar (por um determinado período); ou transferir para terceiros esse direito, por meio de contratos de cessão (transferência de titularidade), além de beneficiá-lo com os retornos gerados a partir do invento (MUNIZ, 2013).

A concepção da produção tecnológica é cercada por desafios técnicos e econômicos que vão desde a viabilidade da proposta até a realização dos investimentos, concepção do protótipo e a sua efetiva produção em escala para atender às diferentes demandas e aos interesses do mercado. Para Santiago et al. (2015), o mercado de tecnologias atrai as organizações não apenas pelo potencial econômico e financeiro gerado a partir da possibilidade de patenteamento, mas, também, em função da vantagem competitiva que gera para seus detentores.

Contudo, para a chegada da tecnologia no mercado, um conjunto de procedimentos estruturados e, ao mesmo tempo complexos, são necessários, sendo estes um dos aspectos que têm impactado às atividades de transferência de tecnologias pelas Instituições Científicas e Tecnológicas (ICTs). Isso, porque, apesar do aumento do número de pedidos de patentes, esses inventos pouco têm sido transferidos destas para o setor produtivo - o qual é responsável pela sua produção em escala, além de se observar um gap entre a academia e as empresas (RODRIGUES; GAVA, 2016; ADRIANO; ANTUNES, 2017).

Nesse contexto, destaca-se que, a fim de que a tecnologia possa ser transferida das ICTs para o setor produtivo, se faz necessária a existência de um elo entre as instituições envolvidas. É nesse cenário que surgem os Núcleos de Inovações Tecnológicas (NITs), que, segundo o artigo $2^{\circ}$, inciso VI, da Lei n. 10.973/2004, consistem em uma "[...] estrutura instituída por uma ou mais ICTs, com ou sem personalidade jurídica própria, que tem por finalidade a gestão de política institucional de inovação e por competências mínimas as atribuições previstas nesta Lei (Redação pela Lei n. 13.243, de 2016) (BRASIL, 2004; 2016).

Os Núcleos possuem papel fundamental para aproximar as IES públicas ao setor produtivo da economia, uma vez que, no Brasil, essa relação ainda é incipiente, impactando no desenvolvimento tecnológico e nos níveis de produção de patentes (LAMANA; KOVALESKI, 2010; PAIVA; SHIKI, 2017). Assim, compete a esses núcleos apoiar a gestão e a execução da política de inovação nas ICTs (BRASIL, 2004; 2016; PAIVA; SHIKI, 2017). Ademais, entre as competências dos NITs, está a prevista no inciso X, da Lei n. 10.973/2004, que prevê o papel de "Negociar e gerir os acordos de transferência de tecnologia oriunda da ICT" (Incluído pela Lei n. 13.243, de 2016). Essa competência consiste no processo de fazer o invento chegar, por meio de um acordo mútuo, ao setor produtivo responsável para tornar a tecnologia acessível à sociedade (DESIDÉRIO; ZILBER, 2014). 
Desse modo, os NITs devem exercer tanto o papel fundamental de aproximação da ICT com o setor produtivo, quanto o de valorar os inventos, de modo a auxiliar o processo inicial de negociação e definir os valores de remuneração das ICTs (BRASIL, 2004; 2016). Segundo Fujino e Stal (2007), nesse processo, é preciso que as IES estejam munidas de informações que sejam coerentes com a expectativa de retornos financeiros e, ao mesmo tempo, em linha com o seu objetivo social.

Para tanto, pressupõe-se que a entidade responsável pelo invento e/ou o inventor tenha realizado etapas significativas, a saber: (i) processo de avaliação qualitativa - consiste na análise do ativo, considerando a viabilidade de licenciamento ao setor interessado e o potencial de comercialização da patente; (ii) valoração (aspecto monetário) - constitui-se na mensuração do valor monetário dos benefícios econômicos e financeiros da patente, a partir da qual pode-se iniciar o processo de negociação e acordos relacionados à exploração comercial; e (iii) análise de valorização - etapa que analisa aspectos de mercado, em particular, potencialidades relacionadas à inserção mercadológica da patente (SOUZA, 2009; TEIXEIRA; MELO; SILVA, 2010).

No que se refere à valoração de patentes, foco da presente pesquisa, ela cumpre papel de apoiar o processo de negociação dos NITs junto ao setor produtivo. É uma das etapas críticas do processo de transferência de tecnologias, pois requer a definição de um valor monetário para um ativo intangível que, em muito dos casos, não possui valores de referência e/ou contratos anteriores disponíveis para consulta no mercado (SOUZA, 2009; TEIXEIRA; MELO; SILVA, 2010; CFC, 2017a; 2017b).

Um dos fatores que evidencia esse desafio, segundo Pita (2010), é que os valores das negociações envolvendo patentes, em muitos dos casos, estão presentes, apenas, nos instrumentos contratuais assinados que não são divulgados, dificultando a aplicação de métodos normalmente utilizados para a avaliação de ativos intangíveis, a exemplo das patentes. Segundo o CFC (2017b, p. 6), os ativos intangíveis, a exemplo das patentes, constituem-se em "[...] um ativo não monetário identificável sem substância física".

Coaduna com essa perspectiva, também, o desconhecimento das metodologias de valoração de patentes e tecnologias que devem ser empregadas para se chegar ao valor monetário do invento. Embora exista um conjunto de metodologias que apoiam o processo de valoração dos ativos intangíveis, segundo Garnica e Torkomian (2009), mensurar o valor monetário de uma patente e definir royalties para a remuneração do detentor do invento constituem um dos maiores entraves na transferência de tecnologia no âmbito dos NITs.

Segundo Guimarães et al. (2014), pesquisas sobre a temática da valoração de tecnologias e patentes ainda são incipientes no Brasil. No caso dos NITs, que são estruturas instituídas por uma ou mais ICTs com a finalidade de gerir a política institucional de inovação, observa-se que não há unanimidade quanto ao uso do método e com relação aos processos de valoração estruturados, o que pode refletir, diretamente, na falta de valoração de inventos nessas instituições no momento do processo de negociação.

Em face do exposto, a presente pesquisa buscou responder à seguinte pergunta: Quais os procedimentos e critérios necessários para a valoração de patentes no âmbito do NITs?

Assim, o objetivo da pesquisa foi investigar os procedimentos e os critérios necessários para a valoração de patentes no âmbito do NITs. Para atingir esse objetivo foi adotada a metodologia de pesquisa exploratória, por meio de uma pesquisa bibliográfica e documental. 
Dessa forma, o descortinamento dos processos necessários à valoração de patentes poderá auxiliar os NITs em processos futuros de negociação de patentes (FUJINO; STAL, 2007). Acrescentam-se a esta discussão as dificuldades na valoração da patente devido à ausência de gestão dos gastos, pelos NITs, associados aos inventos. Esse fato impacta não só o processo inicial de negociação da tecnologia (quando não se tem valores de referência), como também o conhecimento dos investimentos que foram realizados até a concepção do protótipo da tecnologia (FUJINO; STAL, 2007; GUIMARÃES, 2013).

Por conseguinte, conhecer os procedimentos e os critérios de valoração poderá favorecer, também, a criação da cultura da gestão do desenvolvimento de novos inventos nas IES públicas, bem como na definição de procedimentos estruturados de valoração que pode beneficiar as atividades desempenhadas pelos NITs nessas organizações (PITA, 2010).

Diversas pesquisas têm sido desenvolvidas no sentido de discutir metodologias de valoração de ativos, seja para avaliar negócios, como as empresas, seja para avaliar patentes e/ ou tecnologias, entre as quais destacam-se as pesquisas de Ribeiro et al. (2018), Souza (2016), Santiago et al. (2015), Borsatto Júnior, Correia e Gimenes (2015) Teodoro (2015), Guimarães (2013), Fernandes, Silva e Barros Júnior (2011), Pita (2010), as quais serão exploradas mais à frente. Entretanto, tais pesquisas não deram conta de investigar os procedimentos e os critérios para a valoração de patentes no âmbito dos NITs. Assim, a presente pesquisa traz contribuições práticas, na medida em que poderá apoiar os gestores e usuários dos NITs na valoração de patentes e nas contribuições teóricas, ajudando na construção de uma agenda de discussão que aborde metodologia de valoração adaptada à realidade dos NITs.

\section{Revisão da Literatura}

A alocação de recursos em Pesquisa e Desenvolvimento (P\&D) permite às instituições públicas e privadas criarem, desenvolverem e explorarem as suas invenções (SANTIAGO et al., 2015). Essas invenções possibilitam aos desenvolvedores os títulos de Propriedade Intelectual (PI), por meio de patentes, conferindo a eles o direito sobre os resultados decorrentes do invento e o direito a explorar tal invento comercialmente (MUNIZ, 2013).

As patentes consistem em um ativo intangível, contido em documentação jurídica. Além da patente, compõem a classe de ativos intangíveis a marca, os títulos de publicação, os direitos autorais, o software de computador, os direitos de propriedade industrial que não seja a patente, os modelos, protótipos, os ativos intangíveis em desenvolvimento, entre outras (CFC, 2017b).

Segundo Barbosa (2003), as patentes referem-se a um direito de exclusividade da exploração de uma tecnologia dado pelo Estado ao seu titular. Esse direito tem limite de tempo, sendo de 20 anos contados da data do depósito ou 10 anos a partir da concessão - caso a proteção seja patente de invenção, é de 15 anos, contados da data do depósito, ou sete anos a partir da data da concessão caso seja de modelo de utilidade, contato a partir da data de depósito (PIEROZAN; BRUCH, 2017).

Nesse contexto, o patenteamento representa uma forma de captar recursos privados requeridos para transformar o invento em inovação e contribui para minimizar os riscos envolvidos nos investimentos necessários ao amadurecimento da tecnologia e a sua transferência para sociedade. Esse ativo intangível possibilita ainda retornos aos investidores, pois reveste a negociação de maior formalidade e segurança jurídica (QUINTAL; SILVA, 2014). 
Cabe ressaltar que, nesse processo, os Núcleos de Inovação Tecnológica (NITs) desempenham papel fundamental na aproximação e transferência de tecnologia das Instituições Científicas e Tecnológicas (ICTs) para o setor produtivo, já que não cabe às Instituições de Ensino Superior (IES) produzirem em escala os inventos que foram objeto de patentes. Cabe a estas transferir para o setor produtivo para que ele o faça.

De acordo com Santiago et al. (2015), ao desenvolverem tecnologias, de forma interna, as organizações encontram dificuldades em mensurar o valor da tecnologia e, consequentemente, de se beneficiarem dos resultados em decorrência das oportunidades geradas a partir delas. Essas dificuldades são encontradas, também, nas ICTs. Em particular, em relação aos NITs, verifica-se que há dificuldades associadas a valorar os inventos criados nas IES públicas. Isso pode ser observado na pesquisa realizada por Closs et al. (2012), quando eles entrevistaram sete pesquisadores e uma gestora. Nessa referida pesquisa, observou-se que os entrevistados relataram dificuldades em valorar, em negociar com as empresas e em identificar potenciais parceiros comerciais interessados em patentes.

\subsection{Metodologias de Valoração de Propriedade Intelectual}

A valoração de patentes e tecnologias é um dos processos de suma importância para a transferência de tecnologia pelas ICTs públicas para o setor produtivo, pois consiste em atribuir valor monetário ao invento, por meio de métodos de valoração específicos, e pode auxiliar a tomada de decisão dos gestores no momento da negociação e na definição dos valores nos contratos de transferência. Ainda nesse sentido, segundo Paiva e Shiki (2017), com a valoração da patente, é possível conhecer o valor de referência, definir a remuneração da licença e fixar taxas de royalties, o que reforça a necessidade de realizá-las para que se possa conhecer os valores envolvidos nas negociações na esfera dos NITs/ICTs. Além de poder negociar a patente, ressalta-se ainda a possibilidade de valorar visando ao reconhecimento dos ativos intangíveis gerados internamente pelas entidades, conforme os critérios e as premissas definidas pelo CFC (2017a; 2017b).

Com efeito, para que a valoração possa refletir os benefícios esperados do invento, deve-se captar os riscos e as incertezas do processo de inovação tecnológica, com o objetivo de definir valores de referência para uma possível negociação. Dessa maneira, o processo de atribuir valor pode servir de base tanto para a decisão de investimentos no desenvolvimento tecnológico, quanto para embasar a decisão de licenciamento ou cessão do invento. Segundo Pitkethly (1997), a valoração de patentes pretende proporcionar aos que gerenciam o portfólio de patentes um prévio conhecimento do valor para tomada de decisões que sustentem e apoiem o processo de transferência da tecnologia.

Assim, de um modo geral, as metodologias de valoração de ativos partem do princípio de valores anteriores, podendo ser por meio de receita, do preço do produto, das bases históricas de valores, entre outros. No entanto, quando a discussão tem como foco as patentes, sobretudo as de invenção, não existe demonstração de valores anteriores disponíveis no mercado, pois as negociações desdobram-se de forma sigilosa por não se ter mercado ativo de intangíveis (TEODORO, 2015; CFC, 2017a, 2017b).

Reforçando o que destaca Teodoro (2015), o CFC (2017a), por meio da NBC 04 (R4), item 78, prevê que: 
É raro existir mercado ativo para um ativo intangível, mas pode acontecer. Por exemplo, em alguns locais, pode haver mercado ativo para licenças de táxi, licenças de pesca ou cotas de produção transferíveis livremente. No entanto, pode não haver mercado ativo para marcas, títulos de publicações, direitos de edição de músicas e filmes, patentes ou marcas registradas porque esse tipo de ativo é único. Além do mais, apesar de ativos intangíveis serem comprados e vendidos, contratos são negociados entre compradores e vendedores individuais e transações são relativamente raras. Por essa razão, o preço pago por um ativo pode não constituir evidência suficiente do valor justo de outro. Ademais, os preços muitas vezes não estão disponíveis para o público. (CFC, 2017a, p. 19)

Diante desse contexto, conhecer as metodologias de valoração de patentes e tecnologias pode auxiliar na mensuração do valor monetário necessário ao processo de negociação dos inventos. Com efeito, existem diversas metodologias utilizadas para valoração de patentes $e$ tecnologias. São elas: (i) a valoração baseada na abordagem de custo; (ii) a valoração por meio de múltiplos; (iii) a valoração baseada no Fluxo de Caixa Descontado (FCD); (iv) a valoração a partir da Teoria das Opções Reais (TOR); (v) a abordagem de mercado com valoração baseada em Royalties Rates; (vi) a regra dos 25\%; (vii) o modelo alternativo com base no NPT desenvolvido por Pita (2010); (viii) os padrões industriais; (ix) os aportes financeiros; (x) os lucros excedentes; e (xi) a metodologia SENAI para valoração de patentes (PAIVA; SHIKI, 2017; SOUZA, 2016; TEODORO, 2015; COUTO JÚNIOR; GALDI, 2012; SANTOS; SANTIAGO, 2008), os quais encontram-se apresentados, respectivamente, no Quadro 1.

Quadro 1 - Metodologias de Valoração aplicáveis na mensuração de valor monetário de patentes

\begin{tabular}{|c|c|c|c|}
\hline Metodologia & CARACTERÍSTICAS, VANTAGENS E LIMITAÇÕES & PossíveIS APLICAÇÕES & $\begin{array}{c}\text { EstudOS } \\
\text { IDENTIFICADOS }\end{array}$ \\
\hline $\begin{array}{c}\text { (i) } \\
\text { Abordagem } \\
\text { de Custo }\end{array}$ & $\begin{array}{l}\text { Baseia-se nos custos históricos (o que se gastou) } \\
\text { relacionados ao desenvolvimento do invento, bem } \\
\text { como, os custos relacionados à manutenção da patente } \\
\text { junto ao INPI, além de outros materiais relacionados } \\
\text { com o invento. Incipiência de parâmetros para } \\
\text { estimação. Requer monitoramento e controle dos } \\
\text { gastos na fase do desenvolvimento do invento. Um } \\
\text { dos aspectos negativos é que despreza os benefícios } \\
\text { futuros do ativo - geração futura de caixa. }\end{array}$ & $\begin{array}{l}\text { Muito usado pelos } \\
\text { NITs, devido a sua } \\
\text { facilidade na aplicação } \\
\text { e incipiência de dados } \\
\text { financeiros do parceiro } \\
\text { comercial. Voltado para } \\
\text { cessão. }\end{array}$ & $\begin{array}{l}\text { Souza (2016); } \\
\text { Guimarães } \\
\text { (2013); Santos; } \\
\text { Santiago (2008); } \\
\text { Paiva e Shiki } \\
\text { (2017); SENAI; } \\
\text { DN (2018). }\end{array}$ \\
\hline (ii) Múltiplos & $\begin{array}{l}\text { Mensuração de valor monetário com base em } \\
\text { comparações a partir de indicadores de ativos } \\
\text { similares no mercado. Valoração objetiva, mas em } \\
\text { se tratando de tecnologias novas há dificuldades de } \\
\text { identificar ativos similares. }\end{array}$ & $\begin{array}{l}\text { Valoração de Ativos que } \\
\text { possam ser comparáveis } \\
\text { no mercado. Utilizados } \\
\text { por empresas, em } \\
\text { particular em processos } \\
\text { de operações societárias. } \\
\text { Voltado para cessão. }\end{array}$ & $\begin{array}{l}\text { Couto Júnior; } \\
\text { Galdi (2012); } \\
\text { Santos; Santiago } \\
\text { (2008); Paiva e } \\
\text { Shiki (2017). }\end{array}$ \\
\hline
\end{tabular}




\begin{tabular}{|c|c|c|c|}
\hline Metodologia & CARACTERÍSTICAS, VANTAGENS E LIMITAÇÕES & PossíveIS APLICAÇÕES & $\begin{array}{l}\text { ESTUDOS } \\
\text { IDENTIFICADOS }\end{array}$ \\
\hline $\begin{array}{l}\text { (iii) Fluxo } \\
\text { de Caixa } \\
\text { Descontado } \\
\text { (FCD) }\end{array}$ & $\begin{array}{l}\text { Considera o valor do dinheiro no tempo e os riscos } \\
\text { associados aos fluxos de caixas. Utiliza para tanto uma } \\
\text { taxa de risco (custo de capital) para descontar os fluxos } \\
\text { de caixa livres (Receitas menos os gastos) previstos e } \\
\text { estimar os benefícios econômicos e financeiros futuros } \\
\text { dos ativos. Ou seja, considera o Valor Presente Líquidos } \\
\text { dos fluxos de caixas futuros (VPL). Metodologia } \\
\text { amplamente utilizada em análise de viabilidade } \\
\text { econômica e financeira de projetos. A definição da taxa } \\
\text { de desconto deve ser baseada em análises robustas, pois } \\
\text { os benefícios futuros são sensíveis à taxa. Apresenta } \\
\text { simplicidade na utilização, mas pressupõe que os dados } \\
\text { econômicos e financeiros estejam acessíveis para utilizá- } \\
\text { los na valoração. No entanto, não apresenta flexibilidade } \\
\text { gerencial na decisão. }\end{array}$ & $\begin{array}{l}\text { Usado na Valoração de } \\
\text { Empresas e tecnologias } \\
\text { já desenvolvidas. Requer } \\
\text { acesso aos dados da } \\
\text { outra parte, a exemplo } \\
\text { das receitas, custo de } \\
\text { capital associado ao } \\
\text { ativo avaliado (taxa de } \\
\text { desconto). } \\
\text { Voltado para } \\
\text { licenciamento/cessão/ } \\
\text { vendas de ativos. }\end{array}$ & $\begin{array}{l}\text { Ribeiro et al. } \\
\text { (2018); Teodoro } \\
\text { (2015); Fanti et al. } \\
\text { (2015); Pitkethly } \\
\text { (1997); Borsatto } \\
\text { Júnior, Correia } \\
\text { e Gimenes } \\
\text { (2015); Santos; } \\
\text { Santiago (2008); } \\
\text { Ishii (2017); } \\
\text { Chaplinsky e } \\
\text { Payne (2002); } \\
\text { Leal e Santos } \\
\text { (2017); Paiva e } \\
\text { Shiki (2017). }\end{array}$ \\
\hline $\begin{array}{l}\text { (iv) Teoria } \\
\text { das Opções } \\
\text { Reais (TOR) }\end{array}$ & $\begin{array}{l}\text { Consiste na concepção de que a decisão de comprar } \\
\text { ou vender um ativo constitui-se em opção que } \\
\text { concede ao titular o direito de exercê-la ou não. } \\
\text { Apresenta flexibilidade gerencial seja na mensuração } \\
\text { do valor de um projeto/ativo seja como apoio ao } \\
\text { processo da decisão de investimento e na projeção } \\
\text { de resultados esperados. Leva em consideração, } \\
\text { de forma direta, a incerteza. Complexo e requer } \\
\text { conhecimentos avançados de finanças e estatística. }\end{array}$ & $\begin{array}{l}\text { Empresas/Projetos de } \\
\text { P\&D. Pode ser utilizado } \\
\text { pelos NITs na fase de } \\
\text { P\&D, para apoiar a } \\
\text { análise de viabilidade. } \\
\text { Voltado para cessão. }\end{array}$ & $\begin{array}{l}\text { Leal e Santos } \\
\text { (2017); Saito } \\
\text { (2010); Teodoro } \\
\text { (2015); } \\
\text { Fernandes, } \\
\text { Silva, Barros } \\
\text { Júnior (2011); } \\
\text { Paiva e Shiki } \\
\text { (2017); Black e } \\
\text { Sholes (1973). }\end{array}$ \\
\hline $\begin{array}{l}(\mathrm{v}) \\
\text { Abordagem } \\
\text { de mercado } \\
\text { com valoração } \\
\text { baseada em } \\
\text { Royalties Rates }\end{array}$ & $\begin{array}{l}\text { Valoração baseada em taxas de royalties praticadas } \\
\text { no mercado e/ou a partir de royalties aplicados em } \\
\text { ativos comparáveis. }\end{array}$ & $\begin{array}{l}\text { NITs e Empresas } \\
\text { com foco em } \\
\text { remuneração variável } \\
\text { do contrato. Voltado } \\
\text { para licenciamento. }\end{array}$ & $\begin{array}{l}\text { Souza (2016); } \\
\text { Teodoro (2015); } \\
\text { Pitkethly (1997); } \\
\text { Parr (2007). }\end{array}$ \\
\hline $\begin{array}{l}\text { (vi) Regra } \\
\text { dos } 25 \%\end{array}$ & $\begin{array}{l}\text { Essa metodologia prevê que } 75 \% \text { dos ganhos para } \\
\text { o licenciado e } 25 \% \text { para quem licenciou a patente. } \\
\text { Considera que os riscos, em sua maioria, são } \\
\text { assumidos por quem está explorando. }\end{array}$ & $\begin{array}{l}\text { Utilizado, usualmente, } \\
\text { por grandes } \\
\text { empresas, como as } \\
\text { indústrias. Voltado } \\
\text { para licenciamento. }\end{array}$ & $\begin{array}{l}\text { Teodoro (2015); } \\
\text { SENAI; DN } \\
\text { (2018). }\end{array}$ \\
\hline $\begin{array}{l}\text { (vii) Modelo } \\
\text { Alternativo } \\
\text { com base } \\
\text { no NPT }\end{array}$ & $\begin{array}{l}\text { Considera as peculiaridades dos ativos, aspectos } \\
\text { relacionados ao impacto, dos gastos de manutenção } \\
\text { e a maturidade da tecnologia, bem como os } \\
\text { investimentos. }\end{array}$ & $\begin{array}{l}\text { Pode ser usado por } \\
\text { Empresas eNITs. Voltado } \\
\text { para licenciamento e } \\
\text { cessão. }\end{array}$ & $\begin{array}{l}\text { Pita (2010); } \\
\text { Paiva e Shiki } \\
\text { (2017). }\end{array}$ \\
\hline $\begin{array}{l}\text { (viii) Padrões } \\
\text { Industriais }\end{array}$ & $\begin{array}{l}\text { Utiliza parâmetros de mercado, bem como, transações } \\
\text { passadas para apoiar a definição de taxas de royalties. }\end{array}$ & Licenciamento & $\begin{array}{l}\text { SENAI; DN } \\
\text { (2018). }\end{array}$ \\
\hline $\begin{array}{l}\text { (ix) Aportes } \\
\text { Financeiros }\end{array}$ & $\begin{array}{l}\text { Considera do valor dos projetos e dos aportes } \\
\text { relacionados para definir a remuneração das partes. }\end{array}$ & $\begin{array}{l}\text { Licenciamento. Projetos } \\
\text { em que demandam } \\
\text { alocação de recursos } \\
\text { para PD\&I. }\end{array}$ & $\begin{array}{l}\text { SENAI; DN } \\
(2018)\end{array}$ \\
\hline $\begin{array}{l}\text { (x) Lucros } \\
\text { Excedentes }\end{array}$ & $\begin{array}{l}\text { Considera uma taxa de desconto (royalties) que iguale } \\
\text { os ganhos esperados da tecnologia trazidos a valor } \\
\text { presente a zero. }\end{array}$ & Licenciamento & $\begin{array}{l}\text { SENAI; DN } \\
(2018)\end{array}$ \\
\hline $\begin{array}{l}(\mathrm{xi}) \\
\text { metodologia } \\
\text { SENAI para } \\
\text { valoração } \\
\text { de patentes }\end{array}$ & $\begin{array}{l}\text { Indicação do método de valoração a partir da análise } \\
\text { de respostas de um questionário onde se indica quais } \\
\text { metodologias são viáveis e/ou recomendadas. }\end{array}$ & $\begin{array}{l}\text { Aplicado na valoração } \\
\text { pelos NITs e por } \\
\text { empresas }\end{array}$ & $\begin{array}{l}\text { SENAI; DN } \\
\text { (2018). }\end{array}$ \\
\hline
\end{tabular}


De acordo com o SENAI e DN (2018), a aplicação ou não dos métodos mencionados em um determinado processo de valoração de patentes dependerá do tipo de contrato adotado pela ICT, ou seja, se será cessão ou licenciamento. Ademais, as metodologias de valoração já destacadas apresentam graus de complexidade progressivos, associados às variáveis contidas no modelo, sendo os graus mais simples observados no método de custo (i) e o mais complexo no método que usa opções reais (iv). Segundo Pitkethly (1997) e SENAI e DN (2018), dificilmente um modelo contemplará todos os aspectos, sejam eles técnicos ou econômicos, relacionados ao ativo intangível valorado. Assim, nem sempre o mesmo modelo será viável para todas as patentes de uma ICT.

Com relação à metodologia de abordagem dos custos de desenvolvimento (i), conforme Quadro 1, ela se baseia nos gastos envolvidos na tecnologia desenvolvida, ou seja, os gastos afundados ou com base nos custos de substituição - que está relacionado ao gasto realizado na compra ou desenvolvimento do bem. Com base nessa abordagem, a negociação é baseada em um investimento já realizado, ou seja, o valor de uma tecnologia é determinado em função do seu custo de desenvolvimento. Sua principal limitação está no fato de desconsiderar os benefícios econômicos e financeiros futuros da tecnologia, ou seja, a geração de receitas decorrente da negociação do invento (SOUZA, 2016; GUIMARÃES, 2013; SANTOS; SANTIAGO, 2008; PAIVA; SHIKI, 2017).

No que se refere à metodologia de múltiplos (ii), consiste em atribuir valores de forma comparativa, a partir de ativos semelhantes. Segundo SENAI e DN (2018), essa abordagem utiliza uma estratégia semelhante à técnica de benchmarks para mensurar o valor da tecnologia.

Para Couto Júnior e Galdi (2012, p. 139), “[...] o modelo tradicional define que o valor de mercado (ou preço) de uma empresa-alvo $\mathrm{i}$, no ano $\mathrm{t}\left(\mathrm{P}_{\mathrm{it}}\right)$, é diretamente proporcional à variável econômica - lucro, vendas, EBITDA (Earnings Before Interest, Taxes, Depreciation and Amortization), etc. - para a empresa-alvo i, no ano $\mathrm{t}\left(\mathrm{X}_{\mathrm{it}}\right)$ ":

$$
P_{\text {it }}=\beta_{\text {ct }} X_{\text {it }}
$$

Ainda de acordo com o Couto Júnior e Galdi (2012, p. 139), $\beta_{\text {ct }}$ "[...] é o múltiplo da variável econômica das empresas comparáveis "c", no ano "t", definida a partir do conjunto considerado como empresas comparáveis". Assim, o múltiplo pode ser definido a partir das organizações similares à entidade objeto da comparação, conforme a equação 2 , a seguir:

$$
B_{c t}=\frac{P_{i t}}{X_{i t}}
$$

Verifica-se que o cálculo é feito multiplicando o múltiplo $\left(\beta_{\mathrm{ct}}\right)$ (considerando as variáveis de preço - $\mathrm{P}_{\text {it }}$ (valor de mercado do ativo) e as variáveis econômicas das empresas comparáveis $-\mathrm{X}_{\mathrm{it}}$ ) pelos indicadores econômicos da entidade que está sendo analisada, ou seja: Lucro, receitas, volume de vendas, EBITDA, entre outros, obtendo dessa multiplicação o valor do ativo. Essa abordagem, apesar de ser amplamente utilizada no mercado financeiro, possui limitações quando se trata de novas tecnologias e por ser facilmente influenciada pela liquidez do mercado (COUTO JÚNIOR; GALDI, 2012; SANTOS; SANTIAGO, 2008).

No que se refere à metodologia do Fluxo de Caixa Descontado (FCD) (iii), Fanti et al. (2015), Borsatto Júnior, Correia e Gimenes (2015) e Pitkethly (1997) afirmam que essa metodologia 
considera o valor do dinheiro no tempo e os riscos dos fluxos de caixas previstos, utilizando para tanto uma taxa de desconto baseada no risco para descontar os fluxos de caixa previstos. O FCD, segundo Santos e Santiago (2008), tem sido um dos principais métodos utilizados na valoração de tecnologias.

A mensuração do valor presente dos benefícios financeiros futuros de um ativo pode ser feita a partir da seguinte equação que calcula o Fluxo de Caixa Descontados (FCD), onde VA é o Valor do Ativo; i é a taxa de desconto ou taxa de risco do ativo/empreendimento; té o período (tempo) que considera a projeção dos fluxos de caixas; $\mathrm{FC}_{\mathrm{t}}$ é o fluxo de caixa para o tempo t; e n é o número de períodos do fluxo projetado:

$$
V A=\sum_{t=1}^{t=n} \quad \frac{F C_{t}}{(1+i)^{t}}
$$

Entre as desvantagens da metodologia FCD, destacam-se a subjetividade relacionada ao desmembramento nos fluxos de caixa, a mensuração do risco e os impactos causados pelas novas tecnologias, sendo que as taxas de retorno podem sofrer muitas variações, o que pode causar resultados negativos em se tratando de tecnologias novas (TEODORO, 2015). Outrossim, é importante destacar as incertezas da tecnologia que poderão impactar os fluxos de caixas futuros, o que não é captado, também, por meio desse método. Assim, ressalva-se que caso a taxa de desconto não seja bem definida poderá provocar distorções nos fluxos esperados.

De acordo com Ishii (2017), quanto menor o custo de capital, maior é a expectativa do valor de negociação do ativo. Nessa perspectiva, segundo Chaplinsky e Payne (2002), a definição da taxa de desconto é um dos pontos questionáveis na projeção dos FCDs, pois há dificuldades em identificar, de forma precisa, uma taxa que consiga captar todos os riscos do projeto. Assim, Ishii (2017) ressalta que, na definição da taxa, é preciso construir premissas robustas que possam sustentar e fundamentar a valoração do ativo.

Quanto à metodologia com base na Teoria das Opções Reais (TOR) (iv), Saito (2010) afirma se tratar de um modelo que atua na determinação do preço de um projeto/ativo e também tem a finalidade de analisar decisões de investimento, ou seja, ocorre a flexibilidade necessária para o auxílio à tomada de decisões, em relação a ativos, diferentemente da metodologia do FCD. Entretanto, a TOR se diferencia porque ela considera, também, o valor da flexibilidade para reagir a ocorrências não previstas, servindo, portanto, para avaliar projetos de investimento. Essa teoria tem como ponto central a valoração do retorno líquido do projeto, considerando as incertezas.

Cabe frisar que os projetos de P\&D, em fase inicial de desenvolvimento, são os que mais demandam a valoração por meio da TOR, em decorrência do alto grau de incerteza intrínseco a esse tipo de projeto (GUIMARÃES et al., 2014).

Segundo Amaral et al. (2014), essa técnica equipara a patente a uma opção de compra. Uma opção de compra dá ao proprietário, em qualquer momento, o direito de comprar um ativo, que esteja relacionado, até a data de expiração, por certo preço de exercício. Para as opções reais, o ativo relacionado é o valor presente líquido do retorno de um projeto, que pode ser encontrado a partir da equação em que VPL é o Valor presente líquido dos fluxos de caixa futuros menos o valor do investimento na data zero; t é o período (tempo) que considera a projeção de todos os fluxos de caixas; n é o número de períodos do fluxo projetado; i é a taxa 
de desconto ou taxa de risco do ativo/empreendimento; $\mathrm{FC}_{\mathrm{t}}$ é o fluxo de caixa para o tempo t; e $\mathrm{I}_{0}$ é o investimento na data zero:

$$
V P L=\sum_{t=1}^{t=n} \quad \frac{F C_{t}}{(1+i)^{t}}-I_{0}
$$

Essa abordagem de valoração permite decidir pelo abandono e/ou alterar a data do início de um investimento, como também considerar na decisão de investir o contexto micro $e$ macroeconômico para determinar a sua realização, levando o gestor a escolher o "time" ideal para investir, reduzindo as incertezas, os riscos associados e os possíveis resultados negativos (GUIMARÃES, 2013).

Para fins de mensuração do preço de uma determinada opção de compra (call) "C", europeia ${ }^{1}$, este pode ser calculado por meio da equação abaixo, descrita por Souza (2009, p. 75), que se baseia no método de Black e Sholes (1973) e tem como premissa a ausência de arbitragem, ou seja, o retorno sem riscos associados, conforme mostrado a seguir, onde $S$ é o valor presente dos fluxos de caixa do projeto; E é o custo do investimento do projeto; t é o tempo restante para investir; $\sigma$ é o desvio padrão do valor do projeto; r é a taxa de desconto livre de risco; e $\mathrm{N}$ ( ) é a função de distribuição para o custo do projeto:

$$
C=S N \quad\left(\frac{\left(\ln \ln \left(\frac{S}{E}\right)+\left(r+\frac{1}{2} \sigma^{2}\right) t\right)}{L}\right)-E e^{-r t} N\left(\left(\frac{\left(\ln \ln \left(\frac{S}{E}\right)+\left(r+\frac{1}{2} \sigma^{2}\right) t\right)}{L}\right)-\sigma \sqrt{t}\right)
$$

A aplicação da TOR, tanto no âmbito das organizações quanto no âmbito dos NITs, encontra dificuldade devido a sua complexidade. No caso dos NITs, que assim como as empresas são dinâmicos, o volume de atividades e os fluxos relacionados, tanto com o processo do pedido de depósito de patentes, quanto com os relacionados à transferência da tecnologia, dificultam o uso desse método. Ademais, segundo Paiva e Shiki (2017, p. 88), “[...] os recursos muitas vezes são escassos e contam com poucos profissionais".

No que tange à metodologia baseada na análise de mercado (v), Pitkethly (1997) considera os preços de ativos semelhantes no mercado, podendo também serem baseados em taxa de royalties comparáveis que indica a média das taxas de determinado setor, taxas que são utilizadas para acordos de licenciamento.

A aplicação do método de mercado, no entanto, apresenta algumas restrições quanto ao seu uso em processos de inovação, visto que não teria como fazer comparação no mercado. Teodoro (2015) afirma que a comparação com produtos do mercado é um método simples quando a inovação não é radical, pois, sendo uma inovação radical, seria difícil encontrar dados confiáveis no mercado de tecnologia.

Quanto ao método que utiliza a regra dos $25 \%$ (vi), este considera que quem possui licença tem, por direito, participação direta de $25 \%$ dos resultados obtidos com o invento, enquanto o licenciado faz jus a 75\% (TEODORO, 2015). Cabe destacar que, na negociação da transferência da tecnologia, esses percentuais podem ser diferentes e vão depender do acordo estabelecido entre as partes. Segundo o SENAI e DN (2018), a aplicação da Regra dos $25 \%$ pode ser rea-

1 A opção europeia considera que o titular da opção compra só poderá exercer o direito na data do vencimento prevista no contrato. Já a opção américa permite que o titular da opção de compra possa exercer o seu direito a qualquer tempo até a data de vencimento do contrato. 
lizada considerando dois aspectos: (a) redução de custos; e (b) novos lucros. Com relação ao primeiro (a), o cálculo dos royalties pode ser mensurado a partir da seguinte equação.

Taxa de Royalties $=25 \% \times \frac{\text { Custos Reduzido }}{\text { Receita Líquida }}$

Já com relação à segunda possibilidade, que considera a geração de novos lucros, pondera-se a margem de lucro operacional, sendo expresso da seguinte forma.

Taxa de Royalties $=25 \% \times \frac{\text { Lucro Operacional }}{\text { Receita Líquida }}$

É importante ressaltar que há limitações associadas ao método, uma vez que poderá haver assimetria de informações que podem impactar no cálculo de um valor subavaliado (SENAI; DN, 2018).

A realidade dos NITs tem demandado métodos que se adequem as suas particularidades, dinâmica que considera fatores como o tempo, os custos e os níveis de conhecimentos acerca da tecnologia. Nessa perspectiva, esses ambientes têm demandado métodos alternativos.

Nesse sentido, o método de valoração proposto por Pita (2010) (alternativo) (vii) e adaptado à realidade dos NITs na pesquisa de Paiva e Shiki (2017) leva em consideração a natureza e a peculiaridade dos ativos valorados, os gastos de manutenção, os níveis de impactos do invento patenteado (baixo, moderado e alto), os investimentos, a margem de contribuição, além de amortização da tecnologia e a dinamicidade encontrada no âmbito dos NITs, além de ser rápido na projeção dos valores da tecnologia. Nesse método, considera-se, também, o Nível de Prontidão Tecnológica (NPT) que consiste em incorporar a maturidade da tecnologia na valoração.

Esse método foi, inicialmente, desenvolvido por Pita (2010) para apoiar as atividades de transferência de tecnologia por meio da valoração dos inventos de uma empresa do setor Petroquímico no Brasil. Posteriormente, em função da sua aplicabilidade, rapidez e economicidade, fatores marcantes para as atividades dos NITs foram adaptados por Paiva e Shiki (2017) para valoração de patentes do NIT da UFSJ em razão dessas características.

Na concepção do método alternativo, são considerados os aspectos legais da propriedade intelectual, o nível de maturidade tecnológica (NPT) e os indicadores econômicos, que são variáveis importantes nas decisões gerenciais e estratégicas das indústrias, a exemplo da margem de contribuição - que é calculada pela diferença entre o preço de venda (produtos e serviços) e os gastos variáveis unitários e representa o valor gerado por cada produto e/ou serviço que permite cobrir os custos fixos e contribuir na geração dos lucros; o volume de produção (quantidade); e o volume dos investimentos (valores aplicados na concepção do invento) (PITA, 2010; PAIVA; SHIKI, 2017).

Segundo Pita (2010), o conceito de margem de contribuição é plenamente aplicável, também, às patentes e/ou aos documentos de patentes (processos ou produtos), pois podem gerar ganhos para as organizações, sejam eles relacionados aos materiais diretos, a exemplo de matéria-prima, embalagens, entre outros, ou relacionados também aos processos, a exemplo da redução de consumo de água e energia.

Em relação à variável volume, esta relaciona-se com os ganhos de escalas que se pode alcançar com a produção em quantidade de um produto. Assim, Paiva e Shiki (2017, p. 88) 
destacam que "[...] volume traz maior valor para a patente ou documento de patente [...]", sendo este último relacionado a processos.

Ademais, a análise do volume permite compreender o comportamento dos gastos em função das variações no volume de produção. Ou seja, diferentes volumes permitem a análise das variações nos gastos unitários e totais de produção de bens e serviços, dado a inter-relação entre essas variáveis, bem como com as receitas, os custos e as despesas, com reflexos (influência) nos resultados econômicos (lucros) da empresa (MARTINS, 2010; ATKINSON et al., 2008).

No que concerne a investimentos, destacam Paiva e Shiki (2017, p. 88): “[...] o investimento em ativos em produção é significante para a indústria química, porque uma patente que protege contra a cópia tem grande valor bem como um novo processo que substitui um equipamento mais caro, por exemplo".

Ainda, segundo Paiva e Shiki (2017), apesar de o método proposto por Pita (2010) ter sido aplicado no campo da indústria petroquímica, não há restrição de sua aplicação para valorar documento de patente e/ou patentes, pois as variáveis consideradas no modelo, agregadas com o NPT e o aspecto temporal (que considera a perda de valor do ativo intangível - amortização), são variáveis estratégicas e essenciais na tomada de decisão por gestores, por investidores/empresários que decidem comprar uma determinada tecnologia para a sua empresa.

Por conseguinte, o método proposto por Pita (2010, p. 44), adaptado e aplicado para valorar um invento do NIT/UFSJ por Paiva e Shiki (2017, p. 90), pode ser descrito da seguinte forma, conforme equação 8, onde $\mathrm{V}_{\mathrm{i}, \mathrm{t}}$ é o valor da patente i no ano $\mathrm{t}$; $\mathrm{C}_{\text {total }}$ é o custo total de manutenção das patentes em todos os países (custo mínimo); $\mathrm{P}_{\text {margem }}$ é o prêmio no critério margem de contribuição; $\mathrm{P}_{\text {volume }}$ é o prêmio no critério volume; $\mathrm{P}_{\text {investimento }}$ é o prêmio no critério investimento em ativos de produção; $\mathrm{P}_{\text {legal }}$ é o prêmio adicional por concessão no país; e dt é a taxa de depreciação (0,05 a.a.):

$$
V_{i, t}=\left(C_{\text {total }} \times\left(P_{\text {margem }}+P_{\text {volume }}+P_{\text {investimento }}+P_{\text {legal }}\right) x\left(1-d_{t}\right)\right)
$$

Em relação aos NPTs, Segundo Paiva e Shiki (2017), nas indústrias, eles são diferentes quando comparados com os NITs, devendo ser ponderados quando aplicados à realidade dos NITs, pois, nos Núcleos, em muito dos casos, a exemplo do NIT-UFSJ, "[...] são desenvolvidas apenas conceitualmente e em fase laboratorial" (PAIVA; SHIKI, 2017, p. 89).

Segundo Souza (2016), muitas empresas encontram barreiras para valorar sua PI, principalmente pela dificuldade em medir o impacto que sua tecnologia ainda em estágio de amadurecimento causará nos futuros produtos ou serviços. Embora muitas empresas reconheçam a importância da valoração, a complexidade em torno dessa temática leva a uma prática de valoração imprecisa por parte delas.

Em relação ao método de padrões industriais (viii), ele consiste em considerar transações passadas no mercado como referências para as negociações futuras de tecnologias. Para tanto, busca-se taxas de royalties envolvidas em transações anteriores, padrões de royalties utilizados pelo mercado, a exemplo daqueles evidenciados na pesquisa de Parr (2007), entre outros.

Em relação ao método com base em aportes financeiros (ix), considera-se que as partes (licenciante e licenciado) juntas formam uma sociedade que explorarão a tecnologia desenvolvida. Nessa perspectiva, busca-se mensurar as taxas de royalties considerando tanto os benefícios 
econômicos e financeiros futuros do empreendimento como também a contribuição de ambas as partes no propósito para o qual cooperam entre si. Assim, segundo o SENAI e DN (2018), a quota de cada um no empreendimento é fixada com base no Valor Presente Líquido (VPL) do empreendimento e o valor que cada parte alocou no projeto.

Já com relação ao método de valoração com base nos lucros excedentes (x), considera-se o quanto de ganhos (receitas líquidas) a patente pode gerar para o licenciado, cujas receitas são mensuradas utilizando, para tanto, a abordagem de FCD. Assim, os benefícios futuros são valorados e trazidos para o Valor Presente Líquido (VPL), com base em uma taxa de desconto que deve refletir o custo de capital do licenciado. Segundo o SENAI e DN (2018, p. 21), "O retorno do licenciado gerado pelo uso da tecnologia é representado pela taxa de desconto "r" (negociada de antemão entre as partes) e o retorno do licenciante é igual ao VPL do FCD descontado à taxa r negociada".

A abordagem metodológica proposta pelo SENAI em seus processos de valoração (xi) consiste em um conjunto de procedimentos com passo a passo, composto de questões, respondidas a partir de um questionário, que, após combinações, mostra a viabilidade de se utilizar ou não determinada metodologia. Nessa metodologia, as questões consideram o tipo de contrato, as transações anteriores/similares, a relevância da tecnologia e sua importância para o parceiro comercial, as restrições temporais, o acesso a dados dos ganhos da entidade parceira e a maturidade da tecnologia (SENAI; DN, 2018). É meritório frisar que o conjunto de métodos aqui destacados trazem desafios ao ambiente universitário, pois são cercados de complexidade que, em muitos dos casos, dificultam a sua aplicação pelos NITs na valoração da patente.

\section{Metodologia}

Para alcance do objetivo proposto no presente trabalho, realizou-se uma pesquisa exploratória, de natureza bibliográfica, documental e qualitativa baseada em artigos, dissertações, teses, documentos e relatórios técnicos, guias e sites institucionais sobre metodologias de valoração de patentes para a transferência de tecnologia. Segundo Severino (2007), nesse tipo de pesquisa, busca-se levantar informações sobre um determinado tema com a finalidade de delimitar o campo de trabalho.

De acordo com Severino (2007), a pesquisa bibliográfica é realizada a partir de registro disponível resultante de pesquisas anteriores, utilizando-se de dados ou de categorias teóricas já discutidos por outros pesquisadores e devidamente registrados. No que se refere à pesquisa documental, Gil (2002) destaca que esse tipo de pesquisa se vale de matérias que não receberam tratamento analítico, ou que ainda podem ser reelaboradas de acordo com os objetos da pesquisa. Nesse sentido, foram analisadas as referências levantadas a fim de compreender e de descrever os procedimentos e os critérios necessários para a valoração de propriedade intelectual e para descrever as metodologias utilizadas nesse sentido.

Para a operacionalização da presente pesquisa, as etapas foram definidas com a finalidade de alcançar o objetivo proposto.

Na primeira etapa, foi realizado o levantamento dos artigos, das dissertações, das teses, dos documentos e dos relatórios técnicos, além de guias relacionados à valoração de propriedade 
intelectual para a transferência de tecnologia. Nessa etapa, foi possível construir o pressuposto da pesquisa para se verificar com os resultados.

Já na segunda etapa, a partir dos referenciais levantados, realizou-se a descrição das atividades de concepção de um invento e dos procedimentos e critérios necessários para realizar a valoração de patentes.

Na terceira etapa, realizou-se a construção de um fluxo-síntese que versa sobre o processo de concepção e de concessão dos pedidos de patentes, além dos procedimentos e dos critérios para a valoração de patentes pelos NITs, a partir de trabalhos pesquisados.

E, por fim, na quarta e última etapa, foram realizadas as considerações finais da pesquisa.

\section{Resultados e Discussão}

Nesta seção serão apresentados os resultados alcançados e as discussões associadas ao objeto proposto na pesquisa. Assim, estão apresentados os procedimentos e os critérios necessários para a prática de valoração e de negociação de patentes no âmbito dos NITS.

\subsection{Do Processo da Concepção do Projeto à Ełapa de Valoração}

Valorar uma tecnologia é atribuir um valor justo, que represente a melhor descrição do potencial econômico de uma tecnologia diante das informações disponíveis no momento da análise do valor, ou seja, o objetivo da valoração é fornecer um valor esperado e a definição de valores-referência para uma eventual negociação. Esse valor é necessário para dar prosseguimento ao processo de comercialização de uma tecnologia (SANTOS; SANTIAGO, 2008).

O processo de valoração é precedido pela etapa de avaliação. Essa etapa consiste na análise do potencial de comercialização da patente. É por meio da avaliação que se indicam as propostas tecnológicas com potencial comercial que demandarão a valoração para que possam ser comercializadas. A avaliação está relacionada à caracterização técnica e ao potencial de mercado da tecnologia e antecede a valoração no que tange ao potencial comercial dos ativos. Já a valoração constitui-se na mensuração do valor monetário da patente, a partir do qual é possível iniciar a negociação. Em relação à valorização, esta consiste na etapa que analisa aspectos de mercado, em particular, potencialidades relacionadas à inserção mercadológica da patente (TEIXEIRA; MELO; SILVA, 2010; SOUZA, 2009).

Para conhecer os procedimentos e critérios necessários à prática de valoração, é interessante, antes, compreender o processo de desenvolvimento da patente até a etapa de valoração, pois o valor do ativo intangível poderá ser afetado em função dos estágios de desenvolvimento $e$ dos estágios que vão desde o pedido até a concessão do registro.

Assim, para que os NITs possam realizar o processo de valoração para o licenciamento e a transferência de suas patentes e tecnologias, se faz necessário seguir algumas etapas, conforme mostra o fluxo apresentado na Figura 1. 
Figura 1 - Fluxo dos processos de concepção, solicitação, concessão e valoração de patentes

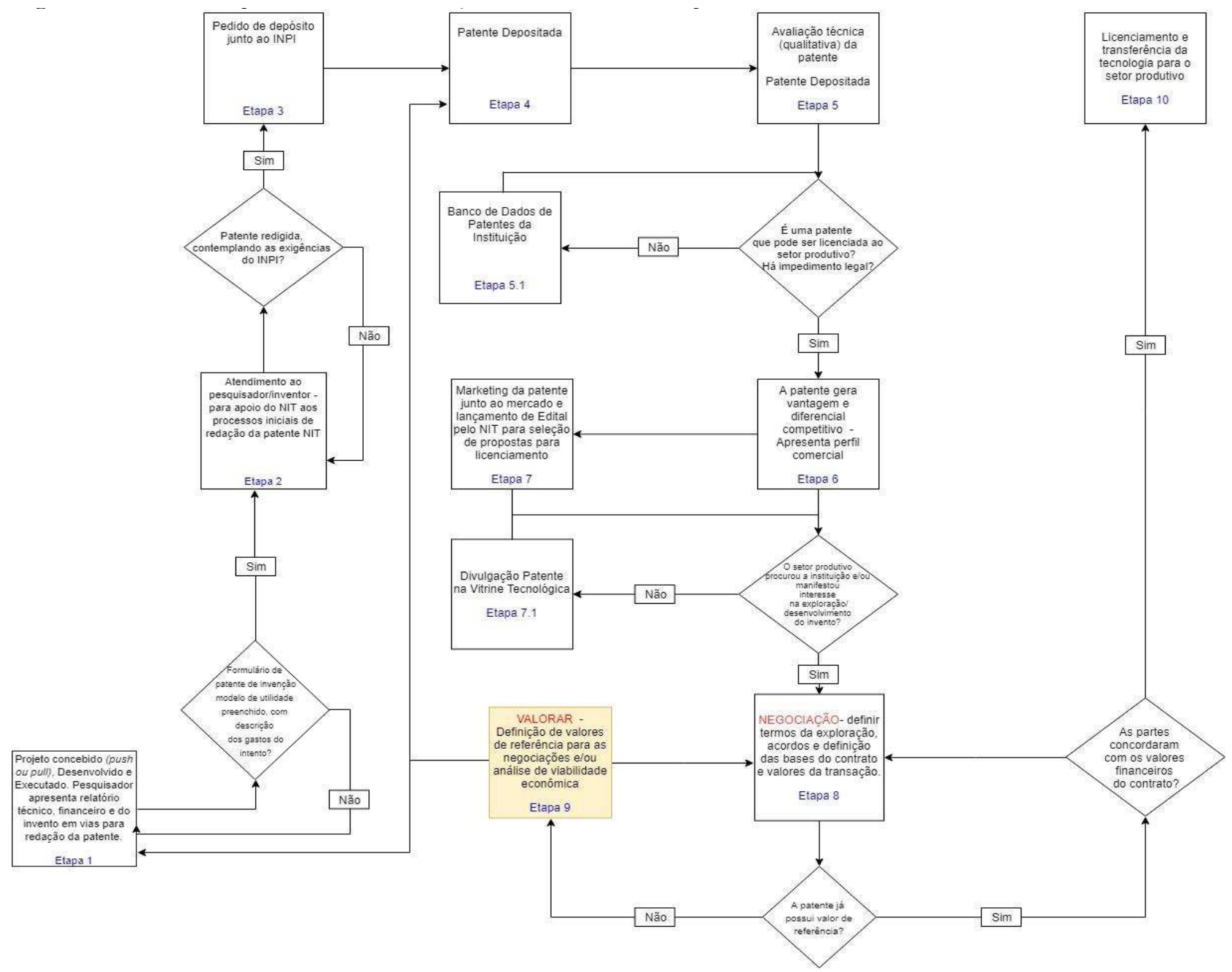

Fonte: Adaptada de Guimarães (2013, p. 131) e de Santiago et al. (2015)

Conforme apresentado na Figura 1, o processo que cerca o desenvolvimento de uma patente se inicia desde a concepção da tecnologia, quando o projeto é elaborado, que corresponde à etapa 1 da Figura 1 . O desenvolvimento tecnológico pressupõe uma política de inovação institucional que norteie a alocação de recursos para tal fim, bem como pode decorrer a partir da indução de mercado, além da aproximação da ICT junto ao setor produtivo. Contudo, cabe destacar que a oferta de tecnologia ao setor produtivo não necessariamente deve ser "empurrada (push process)", visto que os ativos intangíveis, além de serem específicos - se não houver demanda de mercado prévia - poderão se acumular nas vitrines tecnológicas das ICTs e aumentar os seus custos de manutenção que é pulverizado devido à diversidade de patentes desenvolvidas e depositadas.

Desse modo, no start do desenvolvimento da patente, ou seja, ainda na fase de projeto, a própria ICT poderá buscar/aproximar-se do setor produtivo para formular/puxar (pull process) a demanda pelo desenvolvimento da tecnologia, por meio de cooperações e de parcerias, conforme prevê a Lei de Inovação e, assim, diminuir os riscos de não gerar licenciamentos e, consequentemente, recursos para a entidade. Nessa etapa (1), a necessidade de valoração se dá 
por analisar a viabilidade econômica e financeira do investimento, evidenciando, portanto, que a valoração não é uma etapa exclusiva de quando a patente já está registrada e se há interesse do mercado pela exploração.

Na etapa 2, etapa de concepção e desenvolvimento do projeto, com a finalidade de realizar a redação da patente, que deve ser solicitada pelo pesquisador, faz-se necessária a apresentação pelos pesquisadores ao NIT do relatório técnico e financeiro, descrevendo as atividades e os objetivos alcançados com o projeto, detalhamento do invento, dos resultados, testes realizados, estágio e maturidade da tecnologia, a fim de que o pedido de depósito possa ser realizado junto ao Instituto Nacional da Propriedade Intelectual (INPI). Cabe destacar que, nessa etapa, é de fundamental importância o relatório financeiro do projeto, pois esses dados apoiam as atividades de valoração da tecnologia. Nesse caso, os dados auxiliarão na negociação futura da tecnologia.

Atendida a esta etapa 2 , bem como às exigências do INPI, a etapa seguinte é a de solicitação do pedido pelo NIT junto ao INPI (etapa 3). Nessa etapa, é importante o monitoramento do pedido, evitando o não atendimento de demandas necessárias para a concessão do pedido. Na sequência, com o pedido atendido, ou seja, patente concedida (etapa 4), os NITs devem proceder com a avaliação técnica da patente, que implica estudos da análise da potencialidade da tecnologia (TEIXEIRA; MELO; SILVA, 2010; SOUZA, 2009). Ainda nessa etapa, o documento da patente pode ser valorado a fim de estabelecer valores de referências que apoiem a negociação mais à frente.

Para apoiar essas análises, a pesquisa de mercado pode ser realizada (PAIVA; SHIKI, 2017) na etapa de negociação, que vai auxiliar na valoração da patente. Por meio da avaliação técnica e dos estudos mercadológicos, é possível verificar se há restrição no licenciamento. Havendo restrições, a patente deve ficar no banco de dados da ICT. Caso contrário, segue-se para a etapa seguinte, etapa 5 , na qual se apresenta o perfil comercial da patente.

A etapa 6 consiste em analisar a manifestação de interesse do setor produtivo pela exploração comercial. Destaca-se que a valoração pode ocorrer, também, no momento do interesse manifestado por terceiros no licenciamento. Conforme já destacado, o setor produtivo pode manifestar interesse tanto na fase de concepção do projeto quanto na fase em que já houve os trâmites legais junto ao INPI, a patente apresenta perfil comercial e há interesse em licenciar. Nessa etapa, não havendo interessados na exploração comercial, a patente deve ser disponibilizada na Vitrine Tecnológica da ICT, a fim de que seja divulgada para o mercado e para possíveis interessados.

Havendo interesse do setor produtivo, seja manifestado na concepção da tecnologia, seja após disponibilização da patente para exploração, a etapa seguinte, a 7, consiste em estabelecer o processo de negociação. Para tanto, além dos aspectos contratuais e jurídicos, a fim de que seja estabelecido um valor justo, é crucial valorar a tecnologia, caso isso ainda não tenha sido feito. A ausência de valor-base, que vai servir de referência para a negociação, segundo Teodoro (2015), poderá gerar negociações cujo valor não seja o justo. Cumpre destacar que o ato de valorar o invento não depende exclusivamente de a patente já ter sido concedida, pois poderá haver interesse do setor produtivo pela ideia concebida, o que vai demandar da ICT a valoração, haja vista a necessidade de analisar a viabilidade econômica e financeira dos investimentos, informação relevante para ambas as partes. 
Evidentemente que quando a valoração ocorre sem que haja interesse do setor produtivo, ou seja, antes de um processo de negociação, corre-se o risco de se dispor de um valor que não represente mais o valor real da patente, pois a vida útil desta diminui ao longo da vigência da patente. Assim, o valor mensurado até então deverá ser atualizado para eventuais negociações futuras. Além disso, a valoração da patente quando ainda na fase de desenvolvimento e/ou em via de pedidos de depósitos, etapas em que o invento é cercado de incertezas, o valor tende a ser impactado também (FUJINO; STAL, 2007).

Acredita-se que, com processos de aproximação entre a ICT e o setor produtivo, já na fase de concepção/desenvolvimento/execução do projeto, a probabilidade de licenciamento da tecnologia poderá aumentar, o que vai favorecer as premissas estabelecidas na Lei de Inovação e aumentar a interação das ICTs com o setor produtivo, reduzindo as barreiras atuais e os riscos do licenciamento (BRASIL, 2004; DIAS; PORTO, 2013; LUCENA; SPROESSER, 2015; RODRIGUES; GAVA, 2016).

A etapa de negociação é um dos momentos mais significativos do processo de transferência da tecnologia, pois é nessa etapa que a ICT tem a oportunidade de mostrar o valor da tecnologia e de convencer o licenciado de sua importância. Tal valor é mensurado considerando os benefícios econômicos e financeiros gerados pelo invento, a partir dos fluxos financeiros gerados. Nesse sentido, considera-se que a etapa de valoração é crucial para a negociação da tecnologia e para apoiar as análises de viabilidade econômica e financeira. A seguir, serão apresentados os procedimentos necessários e os critérios determinantes para a valoração da patente nos NITs.

\subsection{Da Valoração à Negociação e Transferência da Tecnologia: critérios e procedimentos para a valoração de patentes pelos NITs/ICTs}

Há várias maneiras de se conceber o processo de licenciamento e transferência de tecnologia desenvolvida por uma ICT para o setor produtivo, podendo variar de acordo com a necessidade das instituições e/ou grupos envolvidos.

Com efeito, é preciso saber qual projeto de transferência de tecnologia ou licenciamento a organização pretende implantar e se está de acordo com sua expectativa, assim, é possível traçar o melhor caminho para que o método escolhido venha a atingir os objetivos da empresa. Destarte, é preciso saber quais os tipos de contratos, ou seja, tipos da tecnologia (Cessão ou Licenciamento) poderão ser utilizados pela organização, considerando a concepção de seu projeto (SILVA; VIEIRA JÚNIOR; LUCATO, 2013; SENAI; DN, 2018). 
No que se refere ao licenciamento, este poderá ocorrer mediante o pagamento de royalties ou até mesmo sem contraprestação financeira associada, desde que seja acordado entre as partes (SENAI; DN, 2018).

Assim, para que seja possível definir o método de valoração a ser aplicado na mensuração do valor monetário da patente, é preciso considerar alguns critérios, como os detalhados nos Quadros 2 e 3.

Quadro 2 - Critérios e procedimentos a serem observados para apoiar o processo de valoração da patente nos NITs/ICTs - Aspectos Gerais

\begin{tabular}{|c|c|c|}
\hline Aspectos & CRITÉrIOS & Procedimentos \\
\hline \multirow{8}{*}{ Aspectos Gerais } & $\begin{array}{l}\text { Ciclo de vida da patente } \\
\text { (útil e econômica) }\end{array}$ & $\begin{array}{c}\text { Analisar o impacto nos retornos esperados } \\
\text { e se a curva de retornos tende a ser cada } \\
\text { vez menor com o passar do tempo }\end{array}$ \\
\hline & Aspectos legais & $\begin{array}{l}\text { Considerar a existência de possíveis contestações/ } \\
\text { reinvindicações do invento (litígios) }\end{array}$ \\
\hline & Inovação & Conteúdo de inovação envolvido no invento \\
\hline & $\begin{array}{l}\text { Nível de informações } \\
\text { publicadas sobre o invento }\end{array}$ & Verificar Nível de informações revelados da patente \\
\hline & $\begin{array}{l}\text { Grau de dificuldades da invenção } \\
\text { e Política de propriedade de } \\
\text { intelectual e industrial e o } \\
\text { ambiente desenvolvimento }\end{array}$ & $\begin{array}{l}\text { Analisar aspectos macro e micro (considerar o entorno) } \\
\text { - Conjuntura econômica e seus acontecimentos }\end{array}$ \\
\hline & Mercado & Pesquisar o mercado \\
\hline & Portfólio & $\begin{array}{l}\text { Verificar o grupo de invento ao qual a } \\
\text { patente se vincula (classificação) }\end{array}$ \\
\hline & $\begin{array}{c}\text { Capacidade de a patente ser } \\
\text { usada como barreira de entradas }\end{array}$ & Analisar e discutir a vantagem competitiva no setor \\
\hline
\end{tabular}

Fonte: Adaptado de SENAI e DN (2018), Moresi, Barbosa e Braga (2017), Borsatto Júnior, Correia e Gimenes (2015), Santiago et al. (2015), Sohn, Lee e Ju (2013), Fujino e Stal (2007), Sherry e Teece (2004) e Arora e Fosfuri (2003) 
Quadro 3 - Critérios e procedimentos a serem observados para apoiar o processo de valoração da patente nos NITs/ICTs - Aspectos específicos, contratuais e técnicos

\begin{tabular}{|c|c|c|}
\hline Aspectos & CRItÉRIOS & Procedimentos \\
\hline \multirow{9}{*}{$\begin{array}{l}\text { Aspectos } \\
\text { específicos, } \\
\text { contratuais } \\
\text { e técnicos }\end{array}$} & $\begin{array}{l}\text { Etapas em que o invento } \\
\text { está sendo valorado. }\end{array}$ & $\begin{array}{l}\text { Considerar que a valoração sofre impactos diferentes a } \\
\text { depender do estágio: } \\
\text { a. Etapa de Desenvolvimento (Análise de viabilidade } \\
\text { econômico-financeira); } \\
\text { b. Etapa em que o depósito foi concedido (Antes de } \\
\text { manifestação de interesse); } \\
\text { c. Etapa de manifestação de interesse do setor produtivo } \\
\text { (processo de negociação da exploração comercial). }\end{array}$ \\
\hline & Tipo de contrato & $\begin{array}{l}\text { Verificar como a transferência da tecnologia vai ocorrer: } \\
\text { por meio de contratos de cessão ou licenciamento? } \\
\text { Responder a esta pergunta direciona se será utilizada uma } \\
\text { abordagem de royalties, do valor da tecnologia para a } \\
\text { negociação ou ambos. } \\
\text { Analisar parâmetros considerados nas negociações e peso } \\
\text { das decisões dos gestores no processo. }\end{array}$ \\
\hline & $\begin{array}{l}\text { Transações similares (internas ou } \\
\text { que se conhece no mercado). }\end{array}$ & $\begin{array}{l}\text { Analisar fatos históricos: Existe transações de tecnologia } \\
\text { de natureza similar para utilizá-las como referência para } \\
\text { negociação? }\end{array}$ \\
\hline & $\begin{array}{l}\text { Relevância da patente - análise a } \\
\text { ser feita pelo NIT/ICT que valora. }\end{array}$ & $\begin{array}{l}\text { Gera diferencial e vantagem competitiva para o possível } \\
\text { parceiro? Deve considerar se o projeto é importante para o } \\
\text { parceiro e qual a relevância financeira e estratégica desse } \\
\text { negócio que justifica um investimento considerável de } \\
\text { tempo para valoração. }\end{array}$ \\
\hline & $\begin{array}{l}\text { Peculiaridade das partes } \\
\text { (NITs e parceiros). }\end{array}$ & $\begin{array}{l}\text { Analisar a demanda e sua particularidade; } \\
\text { Analisar a peculiaridade do interessado em explorar a } \\
\text { patente. }\end{array}$ \\
\hline & $\begin{array}{l}\text { Nível de Prontidão } \\
\text { Tecnológica (NPT). }\end{array}$ & $\begin{array}{l}\text { Analisar a maturidade da tecnologia e se está pronta para } \\
\text { produção industrial e aplicação comercial. } \\
\text { A depender do estágio (vide Quadro 3), o valor da } \\
\text { tecnologia será diferente: } \\
\text { a. Estágio de Bancada (1-3); } \\
\text { b. Estágio de Protótipo (4-6); } \\
\text { c. Estágio de escala industrial (7-9). }\end{array}$ \\
\hline & $\begin{array}{l}\text { Aspectos econômicos e financeiros } \\
\text { gerados pela tecnologia - } \\
\text { Potencial de Valorização e } \\
\text { Exploração Econômica. }\end{array}$ & $\begin{array}{l}\text { Considerar a capacidade da tecnologia gerar resultados } \\
\text { econômicos favoráveis ao parceiro com a sua produção } \\
\text { em escala e geração de benefícios financeiros decorrentes } \\
\text { da sua comercialização. } \\
\text { Neste caso, deve-se avaliar os dados econômicos } \\
\text { disponíveis ou disponibilizados pelo parceiro comercial } \\
\text { para fazer as projeções. Ou na ausência os dados } \\
\text { disponíveis no NIT. }\end{array}$ \\
\hline & Tipo do Invento & Patente de Invenção ou patente de modelo de utilidade? \\
\hline & $\begin{array}{l}\text { Gasto realizado pela ICT na } \\
\text { pesquisa e desenvolvimento } \\
\text { do invento. }\end{array}$ & $\begin{array}{l}\text { Controlar todos os gastos relacionados com a criação do } \\
\text { invento e manutenção da patente junto ao INPI. }\end{array}$ \\
\hline
\end{tabular}

Fonte: Adaptado de SENAI e DN (2018), Moresi, Barbosa e Braga (2017), Borsatto Júnior, Correia e Gimenes (2015), Santiago et al. (2015), Sohn, Lee e Ju (2013), Fujino e Stal (2007), Sherry e Teece (2004) e Arora e Fosfuri (2003)

Assim, ressalta-se a necessidade de considerar que o tempo de vida útil e econômica pode impactar no valor da patente, tendo em vista que, à medida que novas tecnologias surgem, o 
invento criado pode perder valor. Como consequência, as instituições que possuem os bens reconhecidos em seu balanço patrimonial deverão mensurar e registrar a perda do valor do ativo intangível em seus registros contábeis.

Os aspectos legais relacionados que impactam no tempo de concessão das patentes devem ser considerados, pois cada etapa desse processo (entre o pedido e a concessão) pode influenciar no valor do invento. É preciso considerar que esse processo é cercado por riscos e incertezas, já que, embora do ponto de vista técnico não ocorram mudanças, é possível haver impactos econômicos - o invento pode criar tendências no mercado e implicar o surgimento de grupos de novas tecnologias. Por fim, aspectos judiciais também devem estar no rol das incertezas em função da possibilidade de ocorrência de contestações (FUJINO; STAL, 2007).

Ainda nesse sentido, em relação ao nível de informações publicadas sobre o invento, o INPI (2017) destaca que, por meio da patente, o inventor ou detentor da nova tecnologia pode impedir uma pessoa de fazer qualquer trâmite relacionado ao objeto de sua patente, em contraparte, o inventor deve detalhar o conteúdo técnico da patente protegida. Com a proteção da patente, além dos ganhos gerados para o detentor, a sociedade também ganha com o conhecimento de uma tecnologia que, se não fosse protegida, permaneceria em sigilo.

Nessa perspectiva, com relação aos aspectos específicos, contratuais e técnicos, os quais consideram aspectos da avaliação da patente, Santiago et al. (2015) destacam que é preciso pensar nos fatores determinantes nesse processo, como os apresentados no Quadro 4, que são complementares aos critérios e aos procedimentos tratados nos Quadros 2 e 3 já apresentados aqui.

Quadro 4 - Fatores determinantes na avaliação da patente

\begin{tabular}{|c|c|}
\hline \multicolumn{1}{|c|}{ FATORES } & ConsiDERAções \\
\hline Elegibilidade & É uma tecnologia que pode ser licenciada? \\
\hline Questões Legais & Há algum impedimento legal para o licenciamento? \\
\hline Concessão & Foi concedida? Quais os países? \\
\hline Questões estratégicas & A patente gera vantagem e diferencial competitivo \\
\hline Mercado & para a empresa? Vale a pena licenciar? \\
\hline
\end{tabular}

Fonte: Adaptado de Santiago et al. (2015) e Fujino e Stal (2007)

Segundo Santiago et al. (2015), a avaliação da elegibilidade não deve ser restrita à liderança de inovação, pois deve ser formada por competências distintas, entre as quais, destaca-se especialistas em patentes, em marketing, em gestão do conhecimento e em pesquisa e desenvolvimento.

O valor da patente, conforme destacam Pita (2010) e Paiva e Shiki (2017), em linha com Santiago et al. (2015), envolve um conjunto de variáveis que precisam estar contidas na modelagem para expressar corretamente o valor financeiro do invento. Assim, os critérios e procedimentos, bem como os fatores já mencionados precisam ser observados para mensurar o valor monetário da patente.

Segundo Arora e Fosfuri (2003), o valor de negociação, ou o preço das tecnologias, depende de fatores que são peculiares aos players do mercado (compradores e vendedores). Deve-se 
considerar, também, conforme destaca Teodoro (2015), que a ausência de um mercado de referência dificulta o acesso aos valores das patentes, o que, às vezes, só é possível quando a patente é negociada no mercado.

Quando a valoração é realizada para fins de negociação, pressupõe-se que as questões técnicas associadas à patente foram atendidas, ou seja, que há potencial comercial para o invento. Considerando que a valoração é a etapa na qual se atribui valor monetário para a patente, faz-se necessário conhecer o status do invento para que um método seja escolhido no processo de valoração. No caso dos NITs, é necessário levantar as informações relacionadas ao desenvolvimento do invento, como os recursos consumidos na sua criação, o volume de investimentos realizados, as taxas de manutenção, a validade temporal da patente, além das informações relacionadas à maturidade da tecnologia.

Nessa perspectiva, a abordagem de fluxo de caixa descontado é uma opção a ser utilizada, mas depende de acesso aos dados que estão de posse das empresas, a exemplo do faturamento e dos gastos dessas organizações. Considerando que a valoração, em um processo de negociação, dá base tanto para o NIT quanto para as empresas, é fundamental para os NITs que a realize a fim de se ter valores de referência e para evitar que o valor negociado não seja o justo, o que ocorre nos casos em que não há conhecimento sobre o valor da patente (TEODORO, 2015).

Outro aspecto que se destaca é que, quando os NITs não possuem valores de referência, tendem a partir para a definição de taxas de royalties, o uso do método de custo como base para a negociação (GUIMARÃES et al., 2014), o que muitas vezes, neste último caso despreza os benefícios financeiros da tecnologia, enquanto, no primeiro caso, pode não considerar os custos associados à criação do invento e da sua manutenção.

Nesse sentido, dada a necessidade de valorar as patentes para se estabelecer valores de referência para a negociação, o que não significa dizer que será o valor final do processo, haja vista que, para que a negociação seja concretizada, as partes devem concordar com o valor estabelecido no contrato. A natureza e a dinâmica dos NITs requerem um método que seja adaptável as suas necessidades e que considerem as informações e características disponíveis no setor. Isso significa dizer que a adoção de métodos, como o FCD, as Opções Reais, os múltiplos, a regra de $25 \%$ (já que nem sempre o desenvolvimento pressupõe o parceiro comercial), se tornam difíceis para os NITs, pois há dificuldades de acesso à informação, como também complexidade no uso dessas metodologias, entre outros aspectos já destacados no Quadro 1.

Com relação aos métodos de custos, que, segundo Guimarães et al. (2013), têm sido utilizados pelos NITs, há limitações que podem contribuir para a subavaliação do valor da tecnologia. Já com relação às taxas de royalties, baseadas nos estudos de Parr (2007), que também têm sido uma prática comum pelos NITs, em alguns casos, combinado com o método de custo, despreza fatores relacionados ao potencial tecnológico, pois parte de uma premissa de taxas-padrão para determinado setor em que se enquadra a tecnologia.

Nesse contexto, a combinação dessas metodologias poderá complementar os fatores de limitação e subsidiar a mensuração do valor de referência. Assim, observa-se que o método adotado por Pita (2010) e adaptado por Paiva e Shiki (2017), apesar de considerar também fatores subjetivos, como prêmios associados à margem de contribuição, volume e investimento, são dados que podem ser estimados pelos NITs, a partir das informações técnicas dos inventos e da maturidade das tecnologias, por meio dos NPTs, acessíveis ao NIT, sendo uma possibilidade para valorar os inventos. 
Essa perspectiva considera o nível de prontidão tecnológica da patente, a margem de contribuição possível com o produto, a vida útil do ativo intangível, o volume, ou seja, a possibilidade de escalabilidade e os aspectos ligados ao grau de similaridade e o tipo de invento, pois esses aspectos impactam no valor do invento no mercado. Como consequência, a partir desses dados, pode-se tanto utilizar métodos alternativos de valoração, a exemplo do modelo de Pita (2010) e Paiva e Shiki (2017), como também outros que podem ser desenvolvidos pela ICTs, considerando as variáveis ilustradas.

Assim, tal metodologia poderá ser utilizada para mensurar valores de referência, ou seja, valores para iniciar o processo de negociação para a exploração econômica $e$ transferência do invento, pois depende de informações que são acessíveis aos NITs e podem ser combinadas com pesquisas de mercado, além de participação efetiva dos pesquisadores envolvidos no invento. Por fim, conforme já ressaltado, é possível combinar mais de um método, a exemplo do que mostraram Guimarães et al. (2013) em pesquisa que evidenciou a utilização pelos NITs de método de custo e royalies rates, como também o FCD com Royalties, entre outros. Contudo, esse é um dos desafios para os NITs que carecem de estrutura e de recursos humanos para tal fim.

É interessante salientar que há vantagens que merecem destaque no processo de exploração comercial dos inventos, em particular para as ICTs públicas, dadas as restrições orçamentárias que vêm sofrendo, seja como fonte de recursos, seja como contribuição para o desenvolvimento científico, tecnológico e econômico. Contudo, embora o processo de valoração gere valores de referência para induzir a negociação e a transferência da tecnologia, há limitações que podem dificultar o processo de avaliação e valoração das tecnologias, conforme mostra o Quadro 5, tendo os NITs o papel crucial para destravar essas questões.

Quadro 5 - Vantagens da valoração e limitações para viabilizar a exploração

\begin{tabular}{|c|c|}
\hline VANTAGENS & LIMITAÇÕES PARA VIABILIZAR A EXPLORAÇÃO \\
\hline $\begin{array}{l}\checkmark \text { Garantia de recursos para } \\
\text { o financiamento de novas } \\
\text { pesquisas; } \\
\checkmark \text { Auxilia a tomada de decisão } \\
\text { para licenciamento de } \\
\text { patentes; } \\
\checkmark \text { Transformação da propriedade } \\
\text { intelectual em produto; } \\
\checkmark \text { Concessão de licenças. }\end{array}$ & $\begin{array}{l}\checkmark \text { Tomada de decisões equivocadas acerca do gerenciamento de portfólio de } \\
\text { tecnologias - manutenção de taxas de inventos que não possui potencial } \\
\text { comercial; } \\
\checkmark \text { Falta de recursos humanos; } \\
\checkmark \text { Falta de domínio dos métodos de valoração; } \\
\checkmark \text { Processos não estruturados o que dificulta o levantamento de informações; } \\
\checkmark \text { Ausência de gerenciamento dos gastos aplicados em pesquisa e } \\
\text { desenvolvimento; } \\
\checkmark \text { Falta de mercado de referência para ativos intangíveis com a finalidade de } \\
\text { análise de tecnologias similares. }\end{array}$ \\
\hline
\end{tabular}

Fonte: Elaborado pelos autores deste artigo a partir de dados da pesquisa

Segundo Fernandes, Gonçalves e Perobelli (2014), as patentes são ativos que estão ganhando importância estratégica, pois possuem características singulares com vantagens competitivas que são diferenciais para as organizações. Teh, Kayo e Kimura (2008) destacam que as patentes são fontes de diferencial competitivo e exercem um papel cada vez mais respeitável na criação de valor para as organizações. 


\section{Considerações Finais}

O objetivo desta pesquisa foi investigar os procedimentos e critérios necessários para a valoração de patentes no âmbito dos NITs. Para tanto, foi adotada a metodologia de pesquisa exploratória, de natureza bibliográfica e documental, por meio de consultas a livros, artigos científicos, teses, dissertações, relatórios técnicos, entre outras fontes de consulta. A abordagem adotada foi a qualitativa e descritiva.

Observou-se que o processo de valoração da propriedade intelectual consiste em atribuir um valor justo ao invento, que represente a melhor descrição do potencial econômico de uma tecnologia diante das informações disponíveis no momento da análise do valor e que apoie o processo de negociação entre as partes.

A partir dos resultados da pesquisa, observou-se que os procedimentos e os critérios que podem ser aplicados para mensurar o valor monetário de patentes no âmbito dos NITs incluem definir o tipo de contrato, a análise ciclo de vida da patente - com a finalidade de analisar o impacto dos retornos esperados. Além disso, é preciso identificar em qual estágio o invento está sendo valorado, considerando que a valoração sofre estágios diferentes, e identificar o nível de prontidão tecnológica, visto que o valor da tecnologia dependerá do estágio em que se encontra o invento. Ademais, é preciso verificar o tipo de invento, o tempo de vida útil da patente, além dos aspectos legais, de modo a verificar se há restrições associadas.

Nesse sentido, destaca-se que o processo de valoração pode ocorrer tanto para subsidiar a análise de viabilidade para decisão do investimento, como também após a concessão da patente $e$, ainda, no momento da negociação.

Assim, cumpre destacar a importância de analisar, previamente, o perfil comercial do invento, antes mesmo da decisão de exploração comercial, de modo a verificar as variáveis associadas ao tipo da tecnologia que são importantes para que a valoração possa ser corretamente realizada, a partir da escolha de uma metodologia aderente ao tipo de tecnologia.

Ainda, nesse sentido, destaca-se a necessidade de verificar as características fundamentais para a decisão da exploração comercial, a exemplo da elegibilidade, dos aspectos legais que podem impedir a negociação e quais as vantagens e diferenciais competitivos gerados pelo invento que se pretende explorar comercialmente.

Por fim, destaca-se que a valoração das patentes é uma etapa fundamental para a negociação do invento e é importante que as invenções desenvolvidas pelas IES públicas sejam transferidas para o setor produtivo, a fim de que possam ser produzidas em escalas, ao mesmo tempo em que podem gerar recursos que devem ser aplicados na ampliação do desenvolvimento de pesquisas científicas e tecnológicas.

Como recomendações de pesquisas futuras, sugere-se aprofundar a discussão sobre a aplicabilidade dos diferentes tipos de metodologias de valoração nos NITs das ICTs públicas e desenvolver manuais que orientem as práticas de valoração e transferência de tecnologia por essas instituições. 


\section{Referências}

ADRIANO, E.; ANTUNES, M. T. P. Proposta para mensuração de patentes. Revista de Administração Contemporânea, Rio de Janeiro, v. 21, n. 1, p. 125-141, 2017.

AMARAL, H. F. et al. Avaliação de ativos intangíveis: modelos alternativos para determinação do valor de patentes. Revista de Gestão, Finanças e Contabilidade, Salvador, v. 4, n. 1, p. 123-143, 2014.

ARAÚJO, L. O. et al. Mapeamento de Propriedade Industrial nos Institutos Federais de Educação do Nordeste. Cadernos de Prospecção, Salvador, v. 11. abr./jun., p. 284-294, 2018.

ARORA, A.; FOSFURI, A. Licensing the market for technology. Journal of Economic Behavior \& Organization, [S.l.], v. 52. p. 277-295, 2003.

ATKINSON, A. A. et al. Contabilidade Gerencial. 2. ed. São Paulo: Atlas, 2008. 812f.

BARBOSA, D. B. Uma introdução à propriedade intelectual. 2. ed. Rio de Janeiro: Lumen Juris, 2003. 951p.

BLACK, F.; SCHOLES, M. The pricing of options and corporate liabilities. The Journal of Political Economy, [S.l.], v. 81, n. 3, May-Jun, p. 637-654, 1973.

BORSATTO JR., J. L.; CORREIA, E. F.; GIMENES, R. M. T. Avaliação de Empresas pelo Método do Fluxo de Caixa Descontado: o caso de uma indústria de ração animal e soluções em homeopatia.

Revista Contabilidade Vista \& Revista, Belo Horizonte, v. 26, n. 2, p. 90-113, maio/ago., 2015.

BRASIL. Lei n. 10.973, de 2 de dezembro de 2004. Diário Oficial [da] República Federativa do Brasil, Brasília, Poder Executivo, 16 de maio de 2004.

BRASIL. Lei n. 13.243, de 11 de janeiro de 2016. Diário Oficial [da] República Federativa do

Brasil, Brasília, Poder Executivo, 12 de janeiro de 2016.

CFC - CONSELHO FEDERAL DE CONTABILIDADE. NBC TG 04 (R4): Ativo Intangível. 2017a. Disponível em: http://www2.cfc.org.br/sisweb/sre/detalhes_sre.aspx?codigo=2017/NBCTG04(R4). Acesso em: 21 set. 2018.

CFC - CONSELHO FEDERAL DE CONTABILIDADE. NBC TSP 08: Ativo Intangível. 2017b. Disponível em: http://www2.cfc.org.br/sisweb/sre/detalhes_sre.aspx?Codigo=2017/ NBCTSP08\&arquivo=NBCTSP08.docx. Acesso em: 26 mar.2019.

CHAPLINSKY, S.; PAYNE, G. Methods of Intellectual Property Valuation. University of Virginia: Darden School Foundation, Charlottesville, 2002. Disponível em: https://papers.ssrn.com/sol3/ papers.cfm?abstract_id $=1279326$. Acesso em: 10 maio 2018.

CLOSS, L. et al. Intervenientes na transferência de tecnologia Universidade-Empresa: o caso PUCRS. Revista de Administração Contemporânea, [S.I.], v. 16, n. 1, p. 59-78, 2012.

COUTO JÚNIOR, C. G.; GALDI, F. C. Avaliação de empresas por múltiplos aplicados em empresas agrupadas com análise de cluster. Revista de Administração da Mackenzie, São Paulo, v. 13, n. 5, set./out. p. 135-170, 2012.

DESIDÉRIO, P. H. M.; ZILBER, M. A. Barreiras no processo de transferência tecnológica entre agências de inovação e empresas: observações em universidades públicas e privadas. Revista Gestão \& Tecnologia, Pedro Leopoldo, MG, v. 14, n. 2, p. 99-124, 2014. 
DIAS, A. A.; PORTO, G.S. Gestão de transferência de tecnologia na inova Unicamp. Revista de Administração Contemporânea, [S.l.], v. 17, n. 3, p. 263-284, 2013.

FANTI, L. D. et al. O Uso das Técnicas de Valor Presente Líquido, Taxa de Interna de Retorno e Payback Descontado: um Estudo de Viabilidade de Investimentos no Grupo Breda Ltda. Desafio Online, [S.l.], v. 3, n. 2, p. 1.141-1.157, 2015. Disponível em: http://www.spell.org.br/documentos/ ver/38292/o-uso-das-tecnicas-de-valor-presente-liquido--taxa-de-interna-de-retorno-e-paybackdescontado--um-estudo-de-viabilidade-de-investimentos-no-grupo-breda-ltda/. Acesso em: 10 maio 2018.

FERNANDES, G.; GONÇALVES, E.; PEROBELLI, F. F. C. Efeitos do investimento em capital intangível e patentes no valor das empresas brasileiras. 2014. Disponível em: https://www. anpec.org.br/encontro/2013/files_I/i8-3ed45185fdd3f0cf55e42ba10bbd08ea.pdf. Acesso em: 9 fev. 2018.

FERNANDES, L. H. S.; SILVA, A. S.; BARROS JÚNIOR, J. P. Aplicação de opções reais na valoração de uma patente para diagnosticar a dengue. Revista Gestão Industrial, Ponta Grossa, v. 7, n. 2, p. 112-134, 2011.

FUJINO, A.; STAL, E. Gestão da propriedade intelectual na universidade pública brasileira: diretrizes para licenciamento e comercialização. Revista de Negócios, [S.I.], v. 12, n. 1, p. 104-120, janeiro/ março, 2007.

GARNICA, L. A.; TORKOMIAN, A. L. V. Gestão de tecnologia em universidades: uma análise do patenteamento e dos fatores de dificuldade e de apoio à transferência de tecnologia no Estado de São Paulo. Gest. Prod., São Carlos, [S.l.], v. 16, n. 4, p. 624, out-dez, 2009.

GIL, A.C. Como elaborar projetos de pesquisa. 4. ed. São Paulo: Atlas, 2002. 176p.

GUIMARÃES, Y. B. T. et al. Valoração de patentes: o caso do núcleo de inovação tecnológica de uma instituição de pesquisa brasileira. Revista Exacta, São Paulo, v. 12, n. 2, p. 161-172, 2014.

GUimARÃES, Y. B. T. Valoração de Patentes em Universidades Públicas do Estado de São Paulo. 2013. 152f. Dissertação (Mestrado em Administração) - Universidade Nove de Julho, São Paulo, 2013.

INPI - INSTITUTO NACIONAL DA PROPRIEDADE INDUSTRIAL. Tabela de retribuições dos serviços prestados pelo INPI. 2017. Disponível em: http://www.inpi.gov.br. Acesso em: 2 abr. 2019.

ISHII, Y. Valuation of Intellectual Property. Japan Patent Office, Asia - Pacific Industrial Property Center, Japan Institute for Promoting Invention and Innovation, 2017. Disponível em: https://www. jpo.go.jp/torikumi_e/kokusai_e/training/textbook/pdf/Valuation_of_Intellec tual_Property.pdf. Acesso em: 10 maio $201 \overline{8}$.

LAMANA, S.; KOVALESKI, J. L. Patentes e o desenvolvimento econômico. In: CONGRESSO VIRTUAL BRASILEIRO DE ADMINISTRAÇÃO, 7., Anais [...], [S.l.], 2010.

LEAL, R. B.; SANTOS, D. F. L. Metodologias para valoração de empresas agroindustriais. Revista de Gestão, Finanças e Contabilidade, Salvador, v. 7, n. 3, p. 340-361, set./dez., 2017.

LUCENA, R. M.; SPROESSER, R. L. Análise da gestão de licenciamento de patentes: estudo multicasos de Instituições Federais de Ensino Superior. Revista de Administração e Inovação, São Paulo, v. 12, n. 3, p. 28-55, 2015. 
MARTINS, Eliseu. Contabilidade de Custos. 10. ed. São Paulo: Atlas, 2010.

MORESI, E. A. D.; BARBOSA, J. A.; BRAGA FILHO, M. O. Modelos para analisar níveis de prontidão de inovação. In: SÉPTIMA CONFERENCIA IBEROAMERICANA DE COMPLEJIDAD, INFORMÁTICA Y CIBERNÉTICA - CICIC 2017, Orlando, FL - USA. Anais [...], Orlando, FL USA, 2017. v. 1. p. 78-81.

MUNIZ, R. M. R. Manual básico manual básico: Propriedade intelectual e transferência de tecnologia. 2. ed. Brasília: Centro de apoio ao desenvolvimento tecnológico, 2013. 129 p.

PAIVA, P. H. A.; SHIKI, S. F. N. Método de valoração de patentes para o NIT-UFSJ. Conexões, Ciência e Tecnologia, Fortaleza, CE., v. 11, n. 3, p. 84-92, nov., 2017.

PARR, R. Royalty Rates for Licensing Intellectual Property. John Wiley \& Sons. 2007.

PIEROZAN, L.; BRUCH, K. L. Análise comparativa entre os INSTDA patente de invenção e de modelo de utilidade e formas de proteção correlatadas: desenho industrial, proteção de novas cultivares e topografia de circuitos integrados. In: VIEIRA, Adriana Carvalho Pinto; ZILLI, Júlio Cesar; BRUCH, Kelly Lissandra (org.). Propriedade intelectual, desenvolvimento e inovação: ambiente institucional e organizações. Criciúma: EDIUNESC, 2017. p. 382-409. DOI: http://dx.doi. org/10.18616/pidi18.

PIRES, E. A.; QUINTELLA, C. M. A. L. T. Política de Propriedade Intelectual e Transferência de Tecnologia nas universidades: Uma perspectiva do NIT da Universidade Federal do Recôncavo da Bahia. Holos, [S.l.], v. 6, p. 178-195, 2015.

PITA, A. C. Análise do valor e valoração de patentes: método e aplicação no setor petroquímico brasileiro. 2010. 90f. Monografia (Graduação em Engenharia de Produção) - Escola Politécnica, Universidade de São Paulo, São Paulo, 2010.

PITKETHLY, R. The Valuation of Patents: A review of patent valuation methods with consideration of option based methods and the potential for further research. New Developments in Intellectual Property: Law and Economics, 1997.

QUINTAL, R. S.; SILVA, B. R. C. S. R. T. Políticas organizacionais de ciência, tecnologia e inovação e gestão da propriedade industrial: uma análise comparativa em Instituições de Pesquisa. Gestão \& Produção, São Carlos. v. 21, n. 4, p. 760-780, 2014.

RIBEIRO, D. L. et al. Avaliação de Empresas pelo Método do Fluxo de Caixa Descontado (FCD): Um estudo em uma Startup na área de Biofármacos. In: PROSPECT\&I, 2018. Maceió, AL, de 13 a 18 de agosto de 2018. Anais [...], Maceió, AL, 2018.

RODRIGUES, F. C. R.; GAVA, R. Capacidade de Apoio à Inovação dos Institutos Federais e das Universidades Federais no Estado de Minas Gerais: um Estudo Comparativo. REAd. Revista Eletrônica de Administração, [S.l.], v. 22, n. 1, p. 26-51, 2016.

SAITO, M. B. Teoria das opções reais: uma aplicação considerando-se o valor da flexibilidade gerencial a projetos de investimento em inovação tecnológica. 2010. 95p. Dissertação (Mestrado em Engenharia de Produção) - Programa de Pós-Graduação em Engenharia de Produção, Universidade Federal de Pernambuco, Recife, Brasil, 2010.

SANTIAGO, L. P. et al. A framework for assessing a portfolio of technologies for licensing out. Technological Forecasting \& Social Change, [S.I.], v. 99. p. 242-251, 2015. 
SANTOS, D. T. E.; SANTIAGO, L. P. Avaliar X Valorar Novas Tecnologias: Desmistificando Conceitos. Radar da Inovação, Instituto Inovação, [S.l.], p. 1-8, 31 jul. 2008. Disponível em: http://pris.com.br/avaliar_x_valorar.pdf. Acesso em: 15 nov. 2017.

SANTOS, D. T. E.; SANTIAGO, L. P. Métodos de valoração de tecnologias. Radar da Inovação, Instituto Inovação, [S.l.], p. 2-11, 2008.

SENAI - SERVIÇO NACIONAL DE APRENDIZAGEM INDUSTRIAL; DN - DEPARTAMENTO NACIONAL. Guia de Aplicação: metodologia para valoração e negociação de PI. Brasília: SENAI/DN, 2018. 62p.

SEVERINO, A. J. Metodologia do trabalho científico. 23. ed. São Paulo: Cortez, 2007. 304p.

SHERRY, E. F.; TEECE, D. J. Royalties, evolving patent rights, and the value of innovation.

Research Policy, [S.I.], v. 33, p. 179-191, 2004.

SILVA, R. C.; VIEIRA JÚNIOR, M.; LUCATO, W. C. Proposta de procedimento de transferência de tecnologia. Revista Exacta, São Paulo, v. 11, n. 1, p. 115-122, 2013.

SOHN, S. Y.; LEE, W. S.; JU, Y. H. Valuing academic patents and intellectual properties: different perspectives of willingness to pay and sell. Republic Of Korea: Elsevier, 2013. p. 13-24.

SOUZA, P. M. Modelos de valoração da propriedade intelectual como indutor de transferência de tecnologia em Universidades Públicas. 2016. 72p. Dissertação (Mestrado em Ciência da Propriedade Intelectual) - Universidade Federal de Sergipe, São Cristóvão, 2016.

SOUZA, R. O. Valoração de ativos intangíveis: seu papel na transferência de tecnologias e na promoção da inovação tecnológica. 2009. 140p. Dissertação (Mestrado em Tecnologia de Processos Químicos e Bioquímicos) - Universidade Federal do Rio de Janeiro. Rio de Janeiro, 2009. Disponível em: http://tpqb.eq.ufrj.br/download/valoracao-de-ativos-intangiveis.pdf. Acesso em: 14 fev. 2018.

TEH, C. C.; KAYO, E. K.; KIMURA, H. Marcas, patentes e criação de valor. Revista de Administração Mackenzie, São Paulo, v. 9, n. 1, p. 86-106, 2008.

TEIXEIRA, L. P.; MELO, R. A. de C.; SILVA, S. A. da. Avaliação e valoração de novas tecnologias: conceitos e diretrizes básicas para o caso das oportunidades de investimento na Rede Passitec. Planaltina, DF: Embrapa Cerrados, 2010. 38 p. (Embrapa Cerrados. Documentos, 287).

TEODORO, A. F. O. Valoração do processo de obtenção e da aplicação da biorremediação com fungos em ambientes impactados por petróleo. 2015. 153p. Tese (Doutorado em Energia e Meio Ambiente) - Universidade Federal da Bahia, Salvador, 2015.

\section{Sobre os Autores}

\section{Ana Rita Fonseca Ferreira}

E-mail: anarffa@hotmail.com

Mestra em Propriedade Intelectual e Transferência de Tecnologia para a Inovação - PROFNIT/IFBA.

Endereço profissional: Instituto Federal de Educação, Ciência e Tecnologia da Bahia, Reitoria, Av. Araújo Pinho, 39, Canela, Salvador, BA. CEP: 40110-150. 


\section{André Luis Rocha de Souza}

E-mail: andresouza@ifba.edu.br

Doutor em Engenharia Industrial PEI/UFBA.

Endereço profissional: Instituto Federal de Educação, Ciência e Tecnologia da Bahia, Campus Salvador, Rua

Emídio dos Santos, s/n, Barbalho, Salvador, BA. CEP: 40110-150. 